\title{
Effects of Creatine and Exercise on Skeletal Muscle of FRG1-Transgenic Mice
}

\author{
Daniel I. Ogborn, Katelyn J. Smith, Justin D. Crane, Adeel Safdar, \\ Bart P. Hettinga, Rossella Tupler, Mark A. Tarnopolsky
}

\begin{abstract}
Background: The FRG1-transgenic mouse displays muscle dysfunction and atrophy reminiscent of fascioscapulohumeral muscular dystrophy (FSHD) and could provide a model to determine potential therapeutic interventions. Methods: To determine if FRG1 mice benefit from treatments that improve muscle mass and function, mice were treated with creatine alone $(\mathrm{Cr})$ or in combination with treadmill exercise (CrEX). Results: The CrEx treatment increased quadriceps weight, mitochondrial content (cytochome c oxidase (COX) activity, COX subunit one and four protein), and induced greater improvements in grip strength and rotarod fall speed. While $\mathrm{Cr}$ increased COX subunits one and four protein, no effect on muscle mass or performance was found. Since $\mathrm{Cr}$ resulted in no functional improvements, the benefits of $\mathrm{CrEx}$ may be mediated by exercise; however, the potential synergistic action of the combined treatment cannot be excluded. Conclusion: Treatment with $\mathrm{CrEx}$ attenuates atrophy and muscle dysfunction associated with FRG1 overexpression. These data suggest exercise and creatine supplementation may benefit individuals with FSHD.
\end{abstract}

\begin{abstract}
RÉSUMÉ: Effets de la créatine et de l'exercice sur le muscle squelettique de souris transgéniques FRG1. Contexte : La souris transgénique FRG1 a une dysfonction et une atrophie musculaires qui ressemble à la dystrophie musculaire fascioscapulohumérale (DFSH), ce qui pourrait constituer un modèle pour l'identification d'avenues thérapeutiques. Méthode : Ces souris ont été traitées au moyen de la créatine seule $(\mathrm{Cr})$ ou de la créatine et de l'exercice sur tapis roulant $(\mathrm{CrEx})$ afin de déterminer si les souris FRG1 peuvent tirer un bénéfice des traitements qui améliorent la masse et la fonction musculaires. Résultats : Le traitement CrEx a augmenté le poids des quadriceps, le contenu mitochondrial (l'activité de la cytochrome c-oxydase (COX), la sous-unité 1 et quatre de la protéine $\mathrm{COX}$ ), et a entraîné une plus importante amélioration de la force de préhension et de la vitesse de chute à l'épreuve du rotarod. Bien que la Cr ait augmenté les sous-unités 1 et 4 de Cox, elle n'a eu aucun effet sur la masse musculaire ou sur la performance. Étant donné que la Cr n'a pas apporté d'amélioration fonctionnelle, les bénéfices de $\mathrm{CrEx}$ pourraient être dus à l'exercice. Cependant, on ne peut exclure la possibilité d'un effet de synergie entre l'exercice et la créatine lors du traitement combiné. Conclusion : Le traitement par CrEx atténue l'atrophie et la dysfonction musculaires associées à la surexpression de FRG1. Selon ces données, l'administration d'un supplément de créatine et l'exercice pourraient être bénéfiques chez les patients atteints de DFSH.
\end{abstract}

Can J Neurol Sci. 2012; 39: 225-231

Fascioscapulohumeral Muscular Dystrophy (FSHD) is associated with the progressive loss of skeletal muscle mass and strength which results in significant functional impairments ${ }^{1}$. Ultimately, this severe muscle atrophy results in a loss of autonomy and a reduction in physical activity, exposing affected individuals to additional co-morbidities associated with a sedentary lifestyle. While exercise has been shown to be beneficial in other muscular dystrophies in both patient and animal models, specific data pertaining to FSHD is lacking. In addition, these studies are often performed on mixed patient groups and lack muscle biopsies to determine molecular outcomes $^{2-5}$, making it difficult to draw specific conclusions on the effects of exercise on FSHD-affected skeletal muscle.

Creatine monohydrate $(\mathrm{Cr})$ supplementation has been widely studied in healthy populations but is also of benefit in certain muscular dystrophies ${ }^{6,7}$. Short-term $\mathrm{Cr}$ supplementation has been shown to increase muscle strength and/or size in various neuromuscular and metabolic disorders ${ }^{8-11}$ and in the mdx mouse model of Duchenne muscular dystrophy ${ }^{12-14}$. Creatine supplementation alone was recently shown to increase fat free

From the Department of Medical Sciences (DIO, KJS), Kinesiology (JDC, AS), Pediatrics and Medicine (BPH, MAT), McMaster University, Hamilton, Ontario, Canada; Department of Molecular Medicine (RT), University of Massachusetts Medical School, Worcester, MA, USA.

Received August 9, 2011. Final Revisions Submitted September 15, 2011. Correspondence to: Mark Tarnopolsky, McMaster University Medical Centre, RM 2H26, 1200 Main St West, Hamilton, Ontario, L8N 3Z5, Canada. 
mass (FFM) and handgrip strength while attenuating the loss of whole body strength due to disease progression in Duchenne muscular dystrophy ${ }^{15}$. However such an effect is not ubiquitous across all dystrophies, as myotonic dystrophy patients derive no functional benefit from $\mathrm{Cr}$ supplementation ${ }^{16,17}$. Consequently, uncertainties still exist regarding the efficacy of $\mathrm{Cr}$ supplementation in the treatment of FSHD, as no literature exists regarding its use specifically in these patients.

The use of exercise as a therapeutic intervention for muscular dystrophies is somewhat controversial as the potential for exercise-induced muscle damage could exacerbate the disease phenotype. On the contrary, low intensity endurance training has been shown to reduce oxidative stress $^{18}$, and promote adaptations similar to wild-type animals in the $\mathrm{mdx}$ mouse ${ }^{19}$. Unfortunately, no data exists from animal models of FSHD, primarily due to the lack of an acceptable model until recently ${ }^{20}$. However, FSHD patients who performed aerobic exercise on a cycle ergometer over 12 weeks had improved maximal aerobic capacity $\left(\mathrm{VO}_{2 \max }\right)$ and greater maximal workloads despite no change in muscle fibre type or capillary density ${ }^{21}$. Similarly, resistance exercise has been shown to be of limited benefit due to marginal improvements in muscle strength; however, the exercise stimulus produced no observable detrimental results ${ }^{2-5}$. While existing data show tolerance and adaptation to an exercise stimulus, the lack of muscle biopsies and often mixed patient groups $^{2}$ does not permit precise conclusion on the effects on FSHD-affected skeletal muscle.

Despite recent intensive investigations into the molecular etiology of FSHD, the precise mechanisms responsible for the marked muscle atrophy and dysfunction remain to be found. As such, effective interventions that act to mitigate or prevent FSHD-associated muscle dysfunction that are viable in the longterm have not been determined. The FSHD Region Gene 1 (FRG1)-transgenic mouse has been established as a novel mouse model of FSHD ${ }^{20,22}$ and represents an opportunity to screen potential therapeutic interventions that may benefit FSHD patients. Consequently we used the FRG1-transgenic mouse to test the effects of $\mathrm{Cr}$ alone or in combination with treadmill exercise (CrEx) on skeletal muscle. As both creatine and exercise are shown to yield beneficial effects on dystrophic skeletal muscle $6,10,12-15$, we hypothesized that $\mathrm{Cr}$ and the $\mathrm{CrEx}$ treatment would result in increased muscle mass and improved mitochondrial and muscle function in FRG1-transgenic skeletal muscle with the CrEx intervention showing the greatest benefit.

\section{Materials AND Methods}

\section{Animal care and ethical approval}

Animals were housed in the McMaster University Central Animal Facility in accordance with the guidelines of the Canadian Council on Animal Care and all procedures were performed with the approval of the McMaster University Animal Review and Ethics Board. Mature (263 \pm 30 days old) FRG1 male and female transgenic mice were obtained that contained three, six or nine copies of the human FRG1 transgene (FRG1-Low, Med, -High respectively), resulting in expression of 10, 30 and 50 times endogenous levels respectively ${ }^{20}$. Animals were pooled into groups based on FRG1 expression such that average transgene expression was equivalent between sedentary-placebo (Control; $n=14)$, sedentary-creatine $(\mathrm{Cr} ; \mathrm{n}=14)$ and creatine- exercise $(\mathrm{CrEx} ; \mathrm{n}=11)$ treated groups (data not shown). $\mathrm{Cr}$ treated animals were provided chow supplemented with $2 \%$ (w/w) creatine monohydrate (AlzChem Trostberg GmbH, Trostberg, Germany). Exercised animals were run on a motorized treadmill (Columbus Instruments, Columbus, $\mathrm{OH}$, USA) three times per week in 30-minute bouts at speeds 12-15 $\mathrm{m} \cdot \mathrm{min}^{-1}$ at $0^{\circ}$ inclination. Following completion of the 52 day training program animals were sacrificed and all muscles were extracted, snap frozen in liquid nitrogen and stored at $-80^{\circ} \mathrm{C}$. Functional testing was performed throughout the study period and included grip strength measurements (Columbus Instruments, Columbus, OH, USA), Rotarod (AccuScan Instruments, Columbus, OH, USA), and spontaneous voluntary running activity (Lafayette Instrument Company, Lafayette, IN, USA).

\section{Western Blotting}

Tibialis anterior muscles were homogenized on ice with glass homogenizers (Wheaton, Millville, NJ, USA) in RIPA buffer (50 $\mathrm{mM}$ Tris HCI pH 7.4, $150 \mathrm{mM} \mathrm{NaCl}, 2$ mM EDTA, 1\% Sodium Deoxycholate, $0.1 \% \mathrm{SDS}$ ) at $25 \mathrm{uL}$ of buffer per milligram of tissue. Protein concentration was determined using the bichinconic acid method as per the manufacturer's recommendations (Pierce, Rockford, IL, USA) with a spectrophotometer (Benchmark Plus, Biorad, Hercules, CA, USA). Complex IV subunit one (COXIV.1; MS404, Mitosciences, Eugene, OR, USA) and four (COXIV.4; MS407, Mitosciences, Eugene, OR, USA) were run on a $12.5 \%$ gel and transferred to nitrocellulose membranes (GE Healthcare, Piscataway, NJ, USA). Membranes were blocked overnight in $5 \%$ fat-free milk in TBST at $4^{\circ} \mathrm{C}$ and incubated for one hour each in primary (COXIV.1 1:3000, COXIV.4 1:2000) and anti-mouse secondary (1:10000; GE Healthcare) antibodies both in $3 \%$ milk at room temperature. Fibronectin protein content (1:1000, ab23750, Abcam, Cambridge, MA, USA) was probed under similar conditions with anti-rabbit secondary antibodies (1:10000, GE Healthcare). All blots were developed with ECL plus (GE Healthcare) and exposed to x-ray film (GE Healthcare). All films were digitized and band density was determined with ImageJ (NIH, Bethesda, Maryland, USA). Protein data is expressed relative to the actin protein content in each sample (\#612657, BD Transduction Laboratories, Franklin Lakes, NJ, USA).

\section{Enzyme Activity}

Mitochondrial electron transport chain cytochrome $c$ oxidase (COX; EC 1.9.3.1) activity was determined on quadriceps homogenates prepared with an electric homogenizer (Ika-Werke, Staufen, Germany, Europe) in 25 uL HEPES buffer (70 mM Sucrose, 220 mM Mannitol, 10 mM HEPES, 1 mM EGTA) per milligram of muscle, as previously described ${ }^{23}$. Absorbance was recorded at $550 \mathrm{~nm}$ in 30 -second intervals at $37^{\circ} \mathrm{C}$ in duplicate for each sample on a spectrophotometer (Cary Bio-300, Varion, Inc., Palo Alto, CA, USA).

\section{RT-PCR}

Total RNA was extracted from approximately $30 \mathrm{mg}$ of quadriceps muscle homogenized in $1 \mathrm{~mL}$ per sample Trizol 
Reagent (Invitrogen, Burlington, ON, Canada). Following homogenization, $0.2 \mathrm{ml}$ of chloroform was added per sample and the resultant clear aqueous phase was transferred to RNeasy spin columns and RNA was isolated as per the manufacturer's instructions (Qiagen, Germantown, Maryland, USA). All samples were DNase treated on the spin columns to prevent contamination with genomic DNA (Qiagen). The RNA concentrations were determined by measuring absorbance of the solution at $260 \mathrm{~nm}$ (ND-1000, Nanodrop, Willmington, DE, USA). Reverse transcription was performed on $100 \mathrm{ng}$ of total RNA primed with random hexamers on a gradient thermocycler (MyCycler, Biorad, Hercules, CA, USA) as per the manufacturer's instructions (Applied Biosystems, Foster City, CA, USA). Real-time polymerase chain reaction (PCR) was performed with the 7300 Real-time PCR system (Applied Biosystems, Foster City, CA, USA) using SYBR ${ }$ Green chemistry $\left(\right.$ PerfeC $_{\mathrm{T}}$ a SYBR ${ }^{\circ}$ Green Supermix with ROX, Quanta Biosciences, Gaithersburg, MD, USA) with standard thermocycling conditions. Primers for FRG1 were utilized as previously described (F: 5'-cgagccgagagtagcagttg-3', R: 5'gcgcgcttaattaatcacttgcagtatctgtcg gcttca-3')(20) and expression of Peroxisome proliferator-activated receptor gamma coactivator-1 $\alpha$ (PGC1 $\alpha$; F: 5'- ttccaccaagagcaagtat-3', R: 3'cgctgtcccatgaggtatt-5') and mitochondrial transcription factor A (Tfam; F: 5'- gaagggaatggg aaaggtaga-3', R:3'- aacaggacatg gaaagcagat-5') was also evaluated. Expression of all transcripts was normalized to $\beta 2$-microglobulin (F: 5 '-ggtctttctggtgcttgtct3', R: 5'-tatgttcggcttc ccattct-3'), which was not influenced by the experimental treatments. Melt curve analysis was performed on all primers to ensure the validity of amplification.

\section{Metabolites}

Quadriceps muscles were freeze-dried for 24 hours before manual powdering and weighing and stored at $-80^{\circ} \mathrm{C}$.
Metabolites were extracted using $0.5 \mathrm{M}$ perchloric acid followed by neutralization with $2.3 \mathrm{M} \mathrm{KHCO}_{3}$. Muscle creatine levels were determined by adding $4 \mu \mathrm{L}$ of either extract/sample, blank or standard in triplicate to appropriate wells of a 96-well black plate. $185 \mu \mathrm{L}$ of buffer ( $50 \mathrm{mM}$ imidazole, $5 \mathrm{mM} \mathrm{MgCl} 2,30 \mathrm{mM}$ $\mathrm{KCl}, 25 \mu \mathrm{M}$ PEP, $200 \mu \mathrm{M}$ ATP, $45 \mu \mathrm{M}$ NADH, $0.24 \mathrm{U} / \mathrm{mL}$ Lactate Dehydrogenase, $0.75 \mathrm{U} / \mathrm{mL}$ Pyruvate Kinase) was added to the wells and the plate was incubated for $15 \mathrm{~min}$ before background fluorescence determination (excitation: $340 \mathrm{~nm}$, emission: $460 \mathrm{~nm})$. Dilute creatine kinase $(2.3 \mu \mathrm{g} / \mathrm{well})$ was added to all wells and the plate was incubated for $1 \mathrm{~h}$ at room temperature before final fluorescence was determined.

\section{Statistical Analysis}

Independent t-tests were utilized to test a priori hypotheses for the effects of $\mathrm{Cr}$ or $\mathrm{CrEx}$ against the sedentary, placebotreated controls. Statistical significance was established as $\mathrm{p} \leq 0.05$ and all data are represented as means \pm SEM.

\section{Results}

Supplementation with $\mathrm{Cr}$ alone increased total muscle creatine $(132 \%$ of control, $\mathrm{p}<0.05)$, and trended toward an increase in CrEx (114\% of control, $\mathrm{p}=0.056)$. Both $\mathrm{Cr}$ alone and CrEx had no effect on bodyweight or condition (data not shown). Quadriceps muscle weight was increased $15.6 \%$ with CrEX $(\mathrm{p}<0.05$, Figure 1) relative to control, but not with $\mathrm{Cr}$ alone. The CrEx treatment resulted in a higher percentage change in grip strength $(146.5 \%, \mathrm{p}<0.05$, Figure 2$)$, rotarod fall speed $(204.1 \%$, $\mathrm{p}<0.001$, Figure 2) and CrEx animals had significantly greater spontaneous exercise when exposed to voluntary running wheels for $24 \mathrm{~h}$ ( $188 \%$ of control, $\mathrm{p}<0.01$, Figure 3$)$. The $\mathrm{Cr}$ treatment induced no significant improvements in any functional variables. Fibronectin protein content was not affected by either treatment (data not shown). Mitochondrial complex IV subunit one

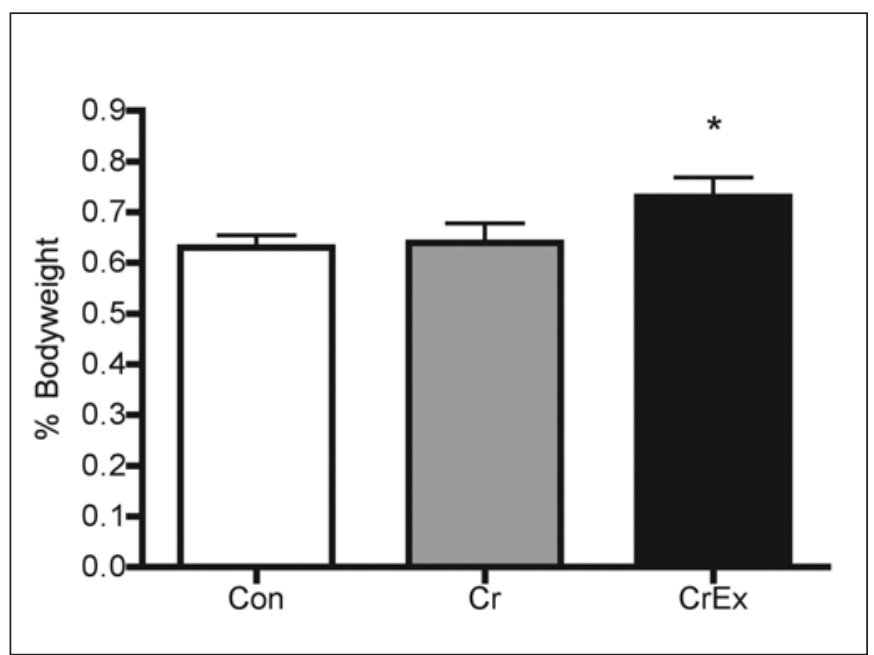

Figure 1: CrEx treatment results in a significant increase in quadriceps muscle mass compared to placebo treated mice. Values are mean \pm SEM. $*$ denotes $P<0.05$ versus control.

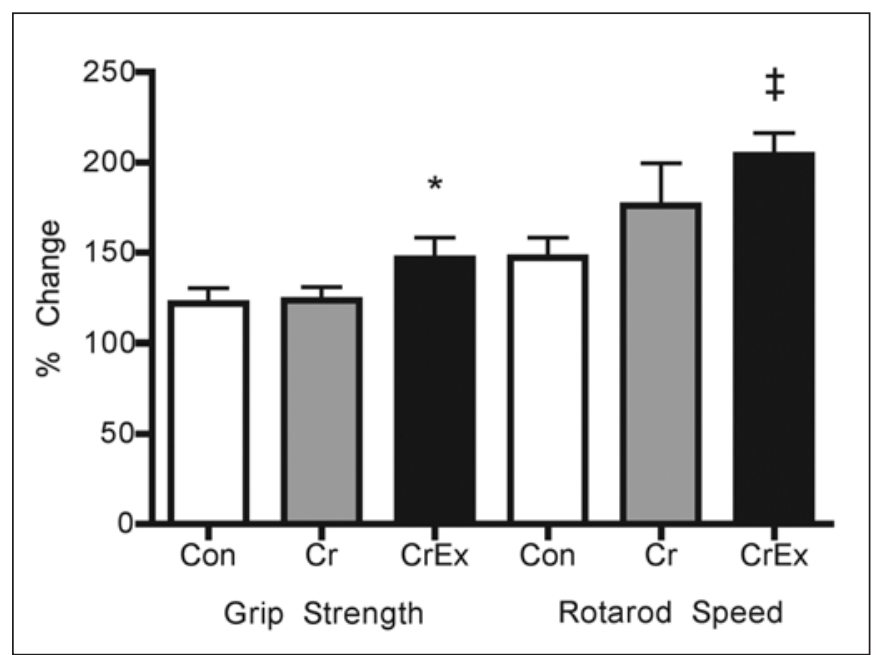

Figure 2: Improvements in grip strength and rotarod fall speed are greater in CrEx when compared to placebo treated animals. Values are mean \pm SEM. * denotes $P<0.05$, $\neq$ denotes $P<0.001$ versus control. 


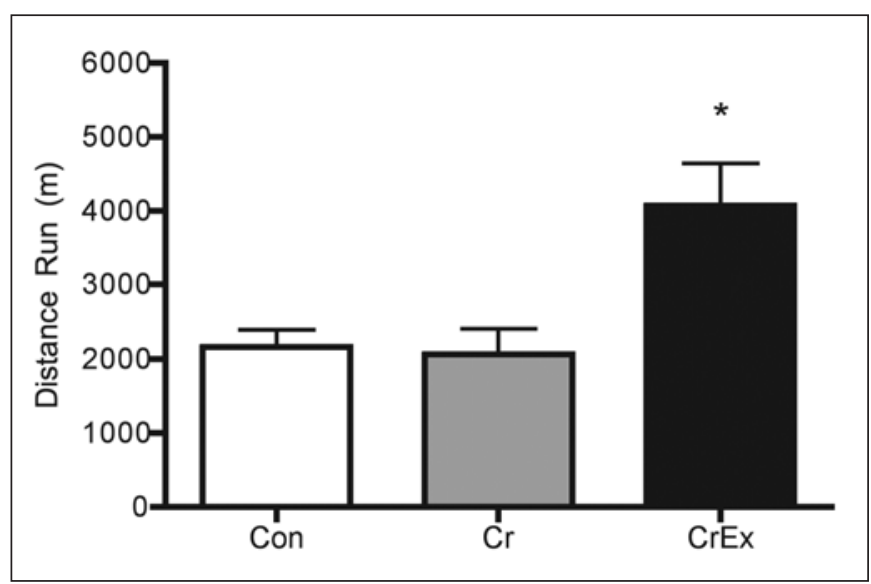

Figure 3: Spontaneous voluntary wheel running over a $24 \mathrm{hr}$ period is significantly higher in CrEx treated FRG1-mice (188\% of Con). * denotes $P<0.05$ versus control. Values represent mean \pm SEM.

(COXIV.1) and four (COXIV.4) protein content was significantly elevated with $\mathrm{Cr}(168 \% \mathrm{p}<0.05,183 \% \mathrm{p}<0.01$ of control respectively; Figure 4) and $\mathrm{CrEx}$ (267\%, 201\% of control respectively, $\mathrm{p}<0.05$; Figure 4 ), however a significant elevation in COX activity was detected only in CrEx (125.5\% of control, $\mathrm{p}<0.05$, Figure 5). Consistent with increased mitochondrial protein content, PGC- $1 \alpha$ mRNA was significantly elevated following $\mathrm{CrEx}(183.3 \%, \mathrm{p}<0.05$, Figure 6) but not $\mathrm{Cr}$, however Tfam mRNA was unchanged with either treatment (data not shown).

\section{Discussion}

The present study demonstrates for the first time that transgenic overexpression of FRG1 does not abolish the mitochondrial adaptations that have been shown to occur in healthy skeletal muscle following exercise. Despite marked

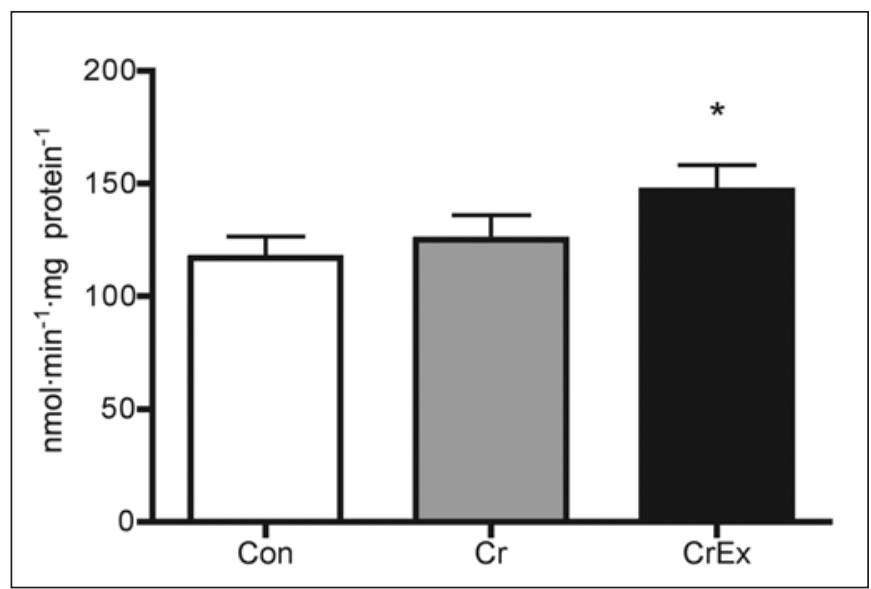

Figure 5: COX activity is significantly elevated following CrEX treatment in FRG1 mice. * denotes $P<0.05$ against control. Values represent mean $\pm S E M$.

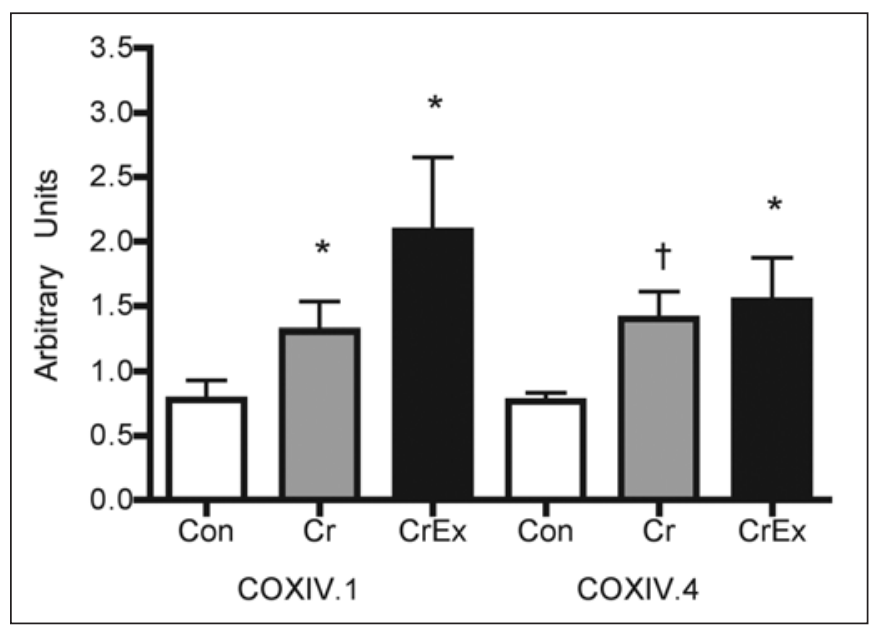

Figure 4: Mitochondrial complex IV subunit one and four proteins are increased following $\mathrm{Cr}$ and CrEx treatment in FRG1 mice. * denotes $P<$ 0.05 , $\dagger$ denotes $P<0.01$ against CON. Values represent mean $\pm S E M$.

muscle dysfunction and exercise intolerance in the FRG1 animals ${ }^{20,22}$, endurance exercise with creatine supplementation resulted in mitochondrial adaptations consistent with those previously documented following exercise in wild-type animals ${ }^{24}$, which coincided with greater enhancements in functional measures. In addition we show that $\mathrm{Cr}$ alone increased the abundance of mitochondrial proteins; however, this did not confer any functional benefits.

\section{Effects of combination creatine and exercise therapy}

This paper is the first to show that despite the marked exercise intolerance of the FRG1-transgenic mouse ${ }^{20}$, low intensity exercise in combination with creatine monohydrate results in improved muscle and mitochondrial function. Exercise

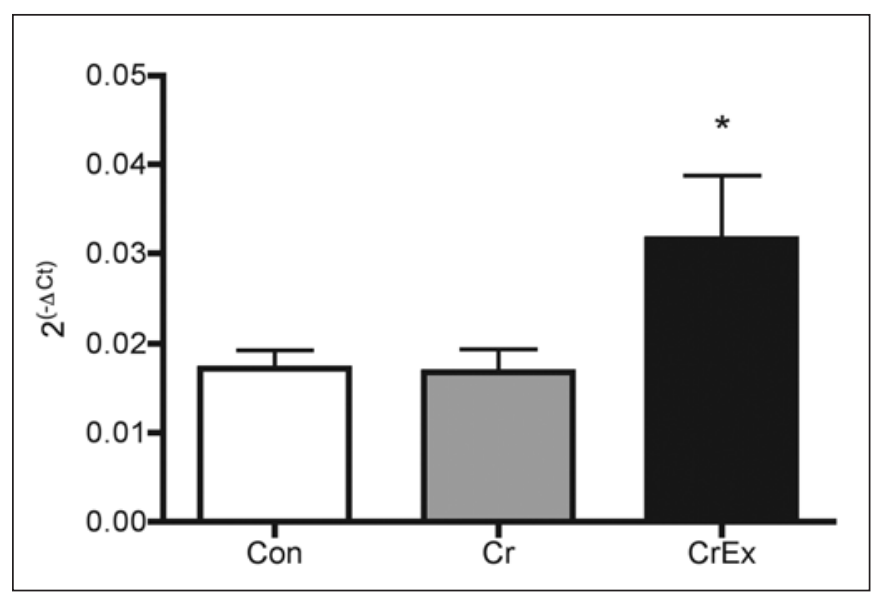

Figure 6: $P G C-1 \alpha m R N A$ is increased with CrEx treatment relative to placebo-treated, sedentary, FRG1 mice. ${ }^{*}$ denotes $P<0.05$ against control. Values represent mean \pm SEM. 
prescription in muscular dystrophies is a controversial area, as care must be taken to prescribe sufficient intensity to produce adaptations without risking damage to the myofibre. Our group and others have previously shown that low-intensity exercise can result in beneficial adaptations in $\mathrm{mdx}$ mice ${ }^{18,25,26}$, and now extend those observations to include the FRG1-transgenic mouse. It should be noted that both the pathological conditions of the mdx and FRG1 mice and the resultant adaptations to endurance exercise are distinct, as the mdx mouse does not show mitochondrial adaptations to exercise ${ }^{18,19}$.

To date, limited work exists regarding the adaptation of FSHD-affected skeletal muscle to exercise. Olsen et $\mathrm{al}^{21}$ found that 12 weeks of low-intensity cycle-ergometer exercise in FSHD patients increased $\mathrm{VO}_{2 \max }$ and maximum workloads with no concurrent changes in muscle fibre type or capillary density. Resistance training, typically associated with increased strength and muscle hypertrophy, has been shown to be well tolerated by FSHD patients ${ }^{2}$, but of marginal benefit due to a lack of induced hypertrophy and minimal gains in strength ${ }^{3-5}$. It is clear that significant work is required to clarify the functional benefits of exercise in FSHD patients and the molecular adaptations that occur following exercise ${ }^{27}$. It is often difficult to interpret the lack of effect of exercise in muscular dystrophies as exercise intensity may be reduced to prevent any potential complications (excessive muscle damage, limited range of motion) but insufficient to produce a detectable adaptation.

In the present work, we found that $\mathrm{CrEx}$ increased muscle weight and muscle strength. While hypertrophy is typically associated with resistance training, under conditions of impaired muscle function and reduced muscle mass (aging, myotonic dystrophy), endurance exercise can result in muscle hypertrophy ${ }^{28-30}$. The present study supports this notion, and while muscle fibre area was not assessed, the fact that muscle function (grip strength, rotarod fall speed) and volitional exercise performance were increased is indicative of improved muscle quality coinciding with elevated muscle weight. Of concern, it is possible that exercise could further damage the dystrophic muscle and result in increased fibrosis in the already fibrotic skeletal muscle ${ }^{20}$, contributing to an increased muscle weight. Contrary to this, we found no detectable increase in Fibronectin protein in either treatment group, a connective tissue component shown to be elevated in FSHD ${ }^{31}$. Consequently, the greater quadriceps mass following $\mathrm{CrEx}$ is functional muscle tissue due to a moderate degree of hypertrophy following $\mathrm{CrEx}$ and not elevated tissue fibrosis, which would be a desirable outcome in the treatment of FSHD.

\section{Effects of creatine supplementation alone}

Creatine supplementation has been shown to stimulate mitochondrial adaptations in dystrophic skeletal muscle. Passaquin and colleagues ${ }^{13}$ found creatine, albeit at a higher dose than used in the present study (10\% of diet), attenuated muscle necrosis and restored mitochondrial oxidative capacity when supplemented over eight to 24 weeks in mdx mice. The results of the present study show that a lower dose of creatine ( $2 \%$ of diet) led to higher protein levels of COX subunits, but such increases were not associated with any significant functional benefit or higher mitochondrial enzyme activity. It is possible that the mitochondrial-derived benefits of creatine supplementation may only occur in muscle with compromised mitochondrial function. Muscle of the mdx mouse has been shown to have impaired oxidative capacity ${ }^{13}$; however, the FRG1-transgenic mouse has not shown mitochondrial impairments (COX-negative, succinate dehydrogenase-hyperreactive fibres) in spite of significant muscle dysfunction, as compared to wild-type mice ${ }^{20}$. With respect to the human form of the disease, little data exists regarding mitochondrial function ${ }^{32,33}$. One case study showed a complex III deficiency in a patient with FSHD $^{32}$ and mitochondrial ultrastructural abnormalities have been seen in FSHD-affected muscle ${ }^{33}$. Nevertheless, significant work is required to determine the contribution of mitochondria to FSHDaffected or FRG1-transgenic muscle pathology or whether any such alterations are simply a consequence of reduced physical activity due to impaired muscle function.

\section{Theories for the mitochondrial effects of Cr supplementation}

In both human and animal models brief periods of $\mathrm{Cr}$ supplementation have been shown to elevate total muscle creatine $10-25 \%^{12,34-36}$, in line with the levels of the present study, and augment phosphocreatine (PCr) levels over nonloaded muscle. More recently additional beneficial effects of $\mathrm{Cr}$ supplementation have been noted, including increased FFM, strength, muscle fibre cross-sectional area and reduced amino acid oxidation ${ }^{37}$. Despite the wealth of data available for $\mathrm{Cr}$ supplementation, relatively little attention has been paid to the potential mitochondrial effects of the supplement. We propose four potential mechanisms through which creatine could alter mitochondrial function/content: 1) stimulation of oxidative phosphorylation to maintain the $\mathrm{PCr} / \mathrm{Cr}$ ratio $^{38-40}$, 2) stimulation of mitochondria through induction of protein synthesis ${ }^{41-44}$ in response to intracellular swelling ${ }^{45-48}$, 3) attenuated protein degradation ${ }^{37}$ and 4) increased basal activity due to restoration of muscle function in diseased muscle. While the present data cannot provide insight into the first three potential mechanisms, the fourth concept of elevated basal activity is not supported, as $\mathrm{Cr}$ treatment alone did not result in greater volitional exercise compared to placebo-treated mice.

\section{Limitations and F uture Directions}

While the present study shows the promising effects of combined creatine and exercise treatment, specific conclusions as to the contribution of each component for the observed effects is not possible due to the study design. As creatine provided no significant functional benefit, future work should focus on the effects of exercise alone or in combination with creatine to determine whether there is a significant synergistic action of the combined treatment, or if the effects in the present study are primarily due to exercise. In addition, while the FRG1-mouse is the best model of FSHD to date, more work is required to determine how well this animal model represents the human form of the disease, and whether the adaptations of FRG1transgenic skeletal muscle accurately represent what could occur in FSHD patients.

\section{Conclusion}

The present study provides data that FRG1-transgenic skeletal muscle is capable of adapting favorably to a 
combination of creatine monohydrate and treadmill exercise. As $\mathrm{Cr}$ resulted in no functional improvements, the positive effects of $\mathrm{CrEx}$ appear to be mediated by exercise, however the potential synergistic action of the combined treatment cannot be excluded. This serves as preliminary evidence indicating that creatine monohydrate and exercise may be a useful therapeutic intervention in FSHD through modulation of skeletal muscle mass and mitochondrial function. Future work is required to determine whether such adaptations occur in the human form of the disease, and whether FSHD-affected skeletal muscle is capable of responding to exercise using the well-characterized exercise-responsive signaling pathways utilized in healthy skeletal muscle.

\section{REFERENCES}

1. Tawil R, Van Der Maarel SM. Facioscapulohumeral muscular dystrophy. Muscle Nerve. 2006 Jul;34(1):1-15.

2. McCartney N, Moroz D, Garner SH, McComas AJ. The effects of strength training in patients with selected neuromuscular disorders. Med Sci Sports Exerc. 1988 Aug;20(4):362-8.

3. van der Kooi EL, Kalkman JS, Lindeman E, et al. Effects of training and albuterol on pain and fatigue in facioscapulohumeral muscular dystrophy. J Neurol. 2007 Jul; 254(7):931-40.

4. van der Kooi EL, Lindeman E, Riphagen I. Strength training and aerobic exercise training for muscle disease. Cochrane Database Syst Rev. 2005(1):CD003907.

5. van der Kooi EL, Vogels OJ, van Asseldonk RJ, et al. Strength training and albuterol in facioscapulohumeral muscular dystrophy. Neurology. 2004 Aug 24;63(4):702-8.

6. Banerjee B, Sharma U, Balasubramanian K, Kalaivani M, Kalra V, Jagannathan NR. Effect of creatine monohydrate in improving cellular energetics and muscle strength in ambulatory Duchenne muscular dystrophy patients: a randomized, placebo-controlled 31P MRS study. Magn Reson Imaging. 2010 Jun;28(5):698-707.

7. Kley RA, Vorgerd M, Tarnopolsky MA. Creatine for treating muscle disorders. Cochrane Database Syst Rev. 2007(1): CD004760.

8. Tarnopolsky MA. Clinical use of creatine in neuromuscular and neurometabolic disorders. Subcell Biochem. 2007;46:183-204.

9. Tarnopolsky M, Martin J. Creatine monohydrate increases strength in patients with neuromuscular disease. Neurology. 1999 Mar 10;52(4):854-7.

10. Louis M, Lebacq J, Poortmans JR, et al. Beneficial effects of creatine supplementation in dystrophic patients. Muscle Nerve. 2003 May;27(5):604-10.

11. Kley RA, Tarnopolsky MA, Vorgerd M. Creatine treatment in muscle disorders: a meta-analysis of randomised controlled trials. J Neurol Neurosurg Psychiatry. 2008 Apr;79(4):366-7.

12. Louis M, Raymackers JM, Debaix H, Lebacq J, Francaux M. Effect of creatine supplementation on skeletal muscle of mdx mice. Muscle Nerve. 2004 May;29(5):687-92.

13. Passaquin AC, Renard M, Kay L, et al. Creatine supplementation reduces skeletal muscle degeneration and enhances mitochondrial function in mdx mice. Neuromuscul Disord. 2002 Feb;12(2):174-82.

14. Pulido SM, Passaquin AC, Leijendekker WJ, Challet C, Wallimann T, Ruegg UT. Creatine supplementation improves intracellular $\mathrm{Ca} 2+$ handling and survival in mdx skeletal muscle cells. FEBS Lett. 1998 Nov 20;439(3):357-62.

15. Tarnopolsky MA, Mahoney DJ, Vajsar J, et al. Creatine monohydrate enhances strength and body composition in Duchenne muscular dystrophy. Neurology. 2004 May 25;62(10): 1771-7.

16. Tarnopolsky M, Mahoney D, Thompson T, Naylor H, Doherty TJ. Creatine monohydrate supplementation does not increase muscle strength, lean body mass, or muscle phosphocreatine in patients with myotonic dystrophy type 1. Muscle Nerve. 2004 Jan;29(1): 51-8.
17. Walter MC, Reilich $\mathrm{P}$, Lochmuller $\mathrm{H}$, et al. Creatine monohydrate in myotonic dystrophy: a double-blind, placebo-controlled clinical study. J Neurol. 2002 Dec;249(12):1717-22.

18. Kaczor JJ, Hall JE, Payne E, Tarnopolsky MA. Low intensity training decreases markers of oxidative stress in skeletal muscle of mdx mice. Free Radic Biol Med. 2007 Jul 1;43(1):145-54.

19. Landisch RM, Kosir AM, Nelson SA, Baltgalvis KA, Lowe DA. Adaptive and nonadaptive responses to voluntary wheel running by mdx mice. Muscle Nerve. 2008 Oct;38(4):1290-303.

20. Gabellini D, D'Antona G, Moggio M, et al. Facioscapulohumeral muscular dystrophy in mice overexpressing FRG1. Nature. 2006 Feb 23;439(7079):973-7.

21. Olsen DB, Orngreen MC, Vissing J. Aerobic training improves exercise performance in facioscapulohumeral muscular dystrophy. Neurology. 2005 Mar 22;64(6):1064-6.

22. D'Antona G, Brocca L, Pansarasa O, Rinaldi C, Tupler R, Bottinelli R. Structural and functional alterations of muscle fibres in the novel mouse model of facioscapulohumeral muscular dystrophy. J Physiol. 2007 Nov 1;584(Pt 3):997-1009.

23. Parise G, Brose AN, Tarnopolsky MA. Resistance exercise training decreases oxidative damage to DNA and increases cytochrome oxidase activity in older adults. Exp Gerontol. 2005 Mar;40(3): $173-80$

24. Boveris A, Navarro A. Systemic and mitochondrial adaptive responses to moderate exercise in rodents. Free Radic Biol Med. 2008 Jan 15;44(2):224-9.

25. Hall JE, Kaczor JJ, Hettinga BP, Isfort RJ, Tarnopolsky MA. Effects of a CRF2R agonist and exercise on mdx and wildtype skeletal muscle. Muscle Nerve. 2007 Sep;36(3):336-41.

26. Wineinger MA, Abresch RT, Walsh SA, Carter GT. Effects of aging and voluntary exercise on the function of dystrophic muscle from mdx mice. Am J Phys Med Rehabil. 1998 Jan-Feb;77(1): 20-7.

27. Voet NB, Bleijenberg G, Padberg GW, van Engelen BG, Geurts AC. Effect of aerobic exercise training and cognitive behavioural therapy on reduction of chronic fatigue in patients with facioscapulohumeral dystrophy: protocol of the FACTS-2FSHD trial. BMC Neurol. 2010;10:56.

28. Coggan AR, Spina RJ, King DS, et al. Skeletal muscle adaptations to endurance training in 60- to 70-yr-old men and women. J Appl Physiol. 1992 May;72(5):1780-6.

29. Orngreen MC, Olsen DB, Vissing J. Aerobic training in patients with myotonic dystrophy type 1. Ann Neurol. 2005 May;57(5): 754-7.

30. Harber MP, Konopka AR, Douglass MD, et al. Aerobic exercise training improves whole muscle and single myofiber size and function in older women. Am J Physiol Regul Integr Comp Physiol. 2009 Nov;297(5):R1452-9.

31. Winokur ST, Chen YW, Masny PS, et al. Expression profiling of FSHD muscle supports a defect in specific stages of myogenic differentiation. Hum Mol Genet. 2003 Nov 15;12(22):2895-907.

32. Slipetz DM, Aprille JR, Goodyer PR, Rozen R. Deficiency of complex III of the mitochondrial respiratory chain in a patient with facioscapulohumeral disease. Am J Hum Genet. 1991 Mar; 48(3):502-10.

33. Munsat TL, Piper D, Cancilla P, Mednick J. Inflammatory myopathy with facioscapulohumeral distribution. Neurology. 1972 Apr;22(4):335-47.

34. Casey A, Constantin-Teodosiu D, Howell S, Hultman E, Greenhaff PL. Creatine ingestion favorably affects performance and muscle metabolism during maximal exercise in humans. Am J Physiol. 1996 Jul;271(1 Pt 1):E31-7.

35. Harris RC, Soderlund K, Hultman E. Elevation of creatine in resting and exercised muscle of normal subjects by creatine supplementation. Clin Sci (Lond). 1992 Sep;83(3):367-74.

36. Hultman E, Soderlund K, Timmons JA, Cederblad G, Greenhaff PL. Muscle creatine loading in men. J Appl Physiol. 1996 Jul;81 (1):232-7.

37. Parise G, Mihic S, MacLennan D, Yarasheski KE, Tarnopolsky MA. Effects of acute creatine monohydrate supplementation on leucine kinetics and mixed-muscle protein synthesis. J Appl Physiol. 2001 Sep;91(3):1041-7. 
38. Smith SA, Montain SJ, Zientara GP, Fielding RA. Use of phosphocreatine kinetics to determine the influence of creatine on muscle mitochondrial respiration: an in vivo 31P-MRS study of oral creatine ingestion. J Appl Physiol. 2004 Jun;96(6): 2288-92.

39. Walsh B, Tiivel T, Tonkonogi M, Sahlin K. Increased concentrations of $\mathrm{P}(\mathrm{i})$ and lactic acid reduce creatine-stimulated respiration in muscle fibers. J Appl Physiol. 2002 Jun;92(6): 2273-6.

40. Walsh B, Tonkonogi M, Soderlund K, Hultman E, Saks V, Sahlin K. The role of phosphorylcreatine and creatine in the regulation of mitochondrial respiration in human skeletal muscle. J Physiol. 2001 Dec 15;537(Pt 3):971-8.

41. Cunningham JT, Rodgers JT, Arlow DH, Vazquez F, Mootha VK, Puigserver P. mTOR controls mitochondrial oxidative function through a YY1-PGC-1alpha transcriptional complex. Nature. 2007 Nov 29;450(7170):736-40.

42. Gough DJ, Corlett A, Schlessinger K, Wegrzyn J, Larner AC, Levy DE. Mitochondrial STAT3 supports Ras-dependent oncogenic transformation. Science. 2009 Jun 26;324(5935):1713-6.

43. Wegrzyn J, Potla R, Chwae YJ, et al. Function of mitochondrial Stat3 in cellular respiration. Science. 2009 Feb 6;323(5915): 793-7.
44. Yokogami K, Wakisaka S, Avruch J, Reeves SA. Serine phosphorylation and maximal activation of STAT3 during CNTF signaling is mediated by the rapamycin target mTOR. Curr Biol. 2000 Jan 13;10(1):47-50.

45. Kutz MR, Gunter MJ. Creatine monohydrate supplementation on body weight and percent body fat. J Strength Cond Res. 2003 Nov; 17(4):817-21

46. Safdar A, Yardley NJ, Snow R, Melov S, Tarnopolsky MA. Global and targeted gene expression and protein content in skeletal muscle of young men following short-term creatine monohydrate supplementation. Physiol Genomics. 2008 Jan 17; 32(2):219-28.

47. Ziegenfuss TN, Lowery LM, Lemon PW. Acute fluid volume changes in men during three days of creatine supplementation. $\mathrm{J}$ Exerc Physiol. 1998;1(3).

48. Vandenburgh HH, Hatfaludy S, Karlisch P, Shansky J. Skeletal muscle growth is stimulated by intermittent stretch-relaxation in tissue culture. Am J Physiol. 1989 Mar;256(3 Pt 1):C674-82. 